\title{
FRAGMENTOS DE UNA HISTORIA NO OFICIAL. A PROPÓSITO DE DOS CUENTARIOS DE JULIETA PINTO
}

\author{
Fragments from unofficial history: \\ Analysis of two Julieta Pinto's short story collection
}

Geaninni Ruiz Ulloa*

\begin{abstract}
RESUMEN
El presente ensayo aborda la narrativa de Julieta Pinto en los cuentarios Los marginados (1970) y A la vuelta de la esquina (1975), los cuales retoman la estética realista de las décadas anteriores. No obstante, a partir de una subjetividad en el discurso sobre lo verosímil, la autora propone una nueva manera de explorar la realidad costarricense a través de la palabra. Ambos libros proponen otra historia - una no oficial -en donde hombres, mujeres y niños anónimos lucha por lo único que tienen, sus vidas.

Palabras clave: realismo, Julieta Pinto, verosimilitud, cuento.
\end{abstract}

\section{ABSTRACT}

This article addresses the narrative of Julieta Pinto in the collection of short stories Marginados (1970) and $A$ la vuelta de la esquina (1975). These collections go back to the realistism aesthetics from previous decades; nevertheless, the author proposes a new way to explore Costa Rican reality through the language and the discourse of verosimilitude. Both books suggest an alternative version of history -a non-official one - in where anonymous men, women and children fight for the only thing they own: their life.

Key words: realism, Julieta Pinto, verosimilitude, tale.

Universidad de Costa Rica. Estudiante de maestría, Escuela de Filología, Lingüística y Literatura. Costa Rica. Correo electrónico: gru_11@hotmail.com Recepción:19/4/16. Acēptación:22/4/16. 


\section{Introducción}

La literatura realista en Costa Rica ha tenido un desarrollo fructífero durante muchos periodos; por ejemplo, la crónica y los cuadros costumbristas están en sus inicios, después se enriquece con el realismo de García Monge y Carmen Lyra y para finalmente, dar un giro por completo, con las novelas del cuarenta. De hecho, para el historiador literario Abelardo Bonilla el nacimiento de la literatura costarricense comienza con el realismo ${ }^{1}$.

Con la fundación de la Segunda República, comienzan nuevas búsquedas $\mathrm{y}$ cuestionamientos sobre el ser nacional, que trajeron consigo una eclosión de propuestas artísticas, en el caso de la literatura, el realismo se convirtió en una posibilidad más para los escritores de la época. Como estética ha propuesto desde sus inicios una exploración sobre las posibilidades de lo verosímil, pues en su afán por reflejar o reproducir una imagen de la sociedad, tergiversa la balanza entre realidad y ficción hacia la primera, presentándose así como reflejo de la realidad.

La narrativa de Julieta Pinto no ha sido estudiado dentro de la crítica costarricense, a pesar de ser una escritora muy prolífera en su obra. Los cuentarios Los marginados (1970) y A la vuelta de la esquina (1975) presentan la cotidianidad y los problemas que experimentan hombres y mujeres pertenecientes a una clase baja, en una Costa Rica de las décadas de los sesentas y setentas. En ese sentido, dialoga con un realismo social de la década anterior, no obstante, aporta elementos textuales que representan una nueva apropiación de lo histórico a partir de una nueva subjetividad que se evidencia en el lenguaje literario.

El propósito de este ensayo es señalar que ambos textos son fragmentos de la diversidad y riqueza literaria que envolvía las décadas posteriores a la fundación de la Segunda República. Asimismo, se plantea que existe una transición en la narrativa de Julieta Pinto, pues transita de la temática rural y de denuncia hacia una representación de lo urbano y de sujetos escindidos. En ese sentido, se podrá en comparación los textos Los Marginados y A la vuelta de la esquina a partir de los siguientes elementos: el espacio textual, los personajes, el uso del lenguaje y la presencia del narrador.

\section{Los marginados}

El verbo marginar viene del latín margināre que significa 'rodear un borde' $\mathrm{u}$ 'orlar' y deriva de la palabra margo que quiere decir margen. En el Diccionario de la Real Academia Española (DRAE), los significados que presenta el verbo se refieren a: la acción de hacer márgenes en textos escritos; o a la acción de prescindir o hacer caso omiso de alguien o de un grupo de personas. Estas definiciones nos señalan que lo marginal está relacionado un movimiento de separación y de expulsión, sea cual sea la razón.

En Los marginados, los personajes son puestos en situaciones límite ${ }^{2}$, que generalmente por su condición subalterna padecen las consecuencias de la exclusión social. Hay una tragedia presente en las historias, pues ante la imposibilidad de acceder a un mejor estatus social, los personajes no tienen otra opción más que resignarse a una sociedad que se encarga de segregarlos.

La temática que predomina el cuentario es la injusticia. Existe una relación importante con las propuestas literarias de Fabián Dobles, Adolfo Herrera y Carlos Luis Sáenz que plantean el texto literario como un medio para la denuncia social. En ese sentido, el cuentario de Pinto es inscribe dentro de un realismo de denuncia, aunque temporalmente no corresponda con los autores anteriores.

El espacio físico que predomina es el rural. Los personajes viven y trabajan en fincas o plantaciones que generalmente pertenecen a externos (patrones o compañías) como se ilustra en los cuentos "El contrato", "El derrumbe" y "El trapiche". En el texto, persiste una noción de la naturaleza como adversaria del ser humano, el cual está llamado a dominarla por medio de la agricultura. Asimismo, se engrandece la figura del labriego sencillo "Tomó un sorbo de agua y 
se frotó el brazo adolorido. La lucha hacia sido dura, la tierra seca por el verano rechazaba el filo que intentaba moldearla" (1970, p. 25). No hay una ubicación geográfica precisa, sin embargo, por los sucintos detalles de la narración la mayoría de los cuentos podrían ambientarse en las cercanías del Valle Central.

Hay dos cuentos que se ubican en la zona atlántica, específicamente en las plantaciones de banano. "El empleo" narra la dificultad de un hombre llamado Pedro Fuentes por encontrar trabajo en una finca, después de haberse vinculado a un sindicato. En un determinado momento, uno de sus capataces le advierte al protagonista mantenerse alejado de cualquier organización sindical

\begin{abstract}
-¿Cómo puede ser usted tan idiota para defender esa chusma? Usted es diferente y tiene posibilidades de llegar a es capataz si se mantiene alejado de todo lo que sea sindicalismo.
\end{abstract}

-Pero ¿la injusticia? - se atrevió a balbucear.

-No sea tonto. Esas cosas suceden desde el mundo es mundo y nadie las va a cambiar. Si quiere un consejo renuncie a ser dirigente y yo le prometo que el año próximo lo nombramos capaz. Eso sí, quítese esas debilidades que no sirven para el mando. La única cosas que se debe tener encuentra es el mayor provecho para la compañía. (1970, p. 115)

La ironía está presente en el cuento, pues aquellos que lucha por la justicia, sufren en carne propia la injusticia. "La guitarra" trata de un hombre llamado Enrique que decide dejar su trabajo en la finca para irse a laborar en una compañía bananera, ya que los salarios que se ofrecen son más altos que los de un jornalero. El cuento narra el día de regreso del protagonista a su casa, quien ha traído dinero y regalos a su esposa e hijos. Hay algunas descripciones sobre las circunstancias que envuelven la vida en las bananeras: "Allí se acostumbró a la ropa mojada y a la comida a medio sancochar; a tumbarse en el tabanco del campamento en medio de un centenar de peones, tan mojados y malolientes como él mismo" (1970, p. 83). Cabe recalcar que las representaciones sobre el espacio de las plantaciones bananeras son similares a las que en otros textos ya se habían enunciado como Mamita Yunai de Carlos Luis Fallas y Bananos y Hombres de Carmen Lyra, en donde la adversidad del clima y las inhumanas condiciones de trabajo hacen del espacio un lugar imposible para vivir.

De la colección de cuentos aquí presente, hay uno en particular que versa sobre la tenencia de la tierra a manos de los campesinos. "Tierra ajena" consiste en la lucha de un hombre por intentar establecer su propia finca en medio de la selva, ya que desea que sus hijos no sean peones y puedan disfrutar de los beneficios de sembrar la tierra que les pertenece al estilo del memorable Ñor Espíritu Santo. Sin embargo, pasado dos años un hombre forastero se presenta a su propiedad y le comunica que su terreno ha sido comprado por una compañía. El siguiente es un diálogo que entabla con su esposa sobre la situación legal de su terreno

\footnotetext{
-Nada se puede hacer. No tengo título todavía y la compañía le compró no sé a quién -¿Le compró? Pero si es nuestro - No pudo dejar de
escapar un grito de protesta.

-Si no tuviera hijos me tendrían que sacar muerto de esta tierra.

$\mathrm{Su}$ voz era ronca, forzada.

¿Y nadie puede ayudarnos?

-Nadie. Dice el abogado que son intereses mayores, que es por el bien del país $(1970$, p. 14)
}

Asimismo, el espacio interno de los cuentos es el hogar, lo anterior se nota principalmente en los cuentos "La guitarra" y "La creciente", pues la casa es sinónimo de la familia, la seguridad y el orden. En el caso de "La creciente", la pérdida del hogar debido a una inundación, provoca la disolución del esquema familiar, ya que también ocurre la muerte del padre, quién por intentar salvar unas gallinas, muere a causa de una cabeza de agua.

Las descripciones de los espacios físicos y de la corporalidad de los personajes son elaboradas por medio de un lenguaje poético antes que por uno referencial. El empleo de figuras literarias como símiles, hipérboles y 
prosopopeyas permite plantear la existencia de una subjetividad en la voz narrativa, que trabaja con una modelación de lo real. Por ejemplo, "divisó el rancho desde lejos. Tenía algo de grotesco entre la vegetación que lo rodeaba. Parecía un extraño pájaro que se había bajado a descansar unos minutos" (1970, p. 10) y "al agacharse para recoger leña y atizar el fogón, mostró sus pechos flácidos, escurridos, como la bolsa de chorrear café que descansaba en el moledero" (1970, p. 26). En el primer símil, se señala la hostilidad de un espacio natural adverso al ser humano y la irrupción del rancho como elemento inusual. En la segunda comparación, los pechos de la mujer evidencian el envejecimiento de la figura femenina y el desgaste en el cuerpo a causa del arduo trabajo doméstico.

Hay un uso tímido del lenguaje coloquial, casi no se utilizan frases o léxico de uso popular. Esto está influenciado por los elementos poéticos que se presentan en los cuentos. Aunque, hay diálogos en donde participan los personajes, generalmente, sus pensamientos y sentimientos se expresan por medio del narrador que tiene un control absoluto del mundo narrado. Por ejemplo: "Abrió los ojos y sintió un viento frío que penetraba por la ventana de vidrios quebrados anunciando la lluvia (...) Saltó de la cama. Tenía esa costumbre desde pequeño, era el único modo de cambiar la cobija caliente por el frío de la habitación" (1970, p. 61).

Solo en uno de los dieciocho cuentos que conforman el texto, hay una participación directa de las voces de los personajes. En "El amigo", el protagonista narra cómo se involucra sexualmente con la hija de su esposa, con la que no comparte un vínculo sanguíneo. Ante el escándalo social, el hombre decide quitarse la vida y le pide a su amigo - quien escucha pacientemente - treinta pesos para comprar una pistola.

Los protagonistas de los cuentos generalmente son hombres que trabajan para mantener a sus familias, las cuales pertenecen a una condición social baja. No poseen tierras propias y son numerosas en miembros. Asimismo, solo cuentan con el salario del padre, ya que en el modelo de familia que se sigue, la figura masculina predomina y cumple con roles de ser proveedor y máxima autoridad del hogar; en cambio la figura femenina es secundaria y se encarga del hogar y la crianza. Los hijos, dependiendo del género, tienen tareas específicas, pero siempre se encuentran a merced de la voluntad paterna. El valor presente en las figuras masculinas es el trabajo. No obstante, la dificultad por encontrar un trabajo que les permita mantener a sus familias provoca una crisis en la consolidación de la figura paterna.

En "La reunión", un grupo de jornaleros discute en la pulpería del pueblo qué acciones tomar ante el hecho de estar desempleados durante meses

-Todos son unos desgraciados. Me salieron con mil carajadas, que el patrón, que el pleito, qué se yo, total para decirme que estemos tranquilos que algún día nos pagan.

-Pero, ¿les dijiste que no tenemos qué comer?

-Pues claro, ¿qué querés que les diga? Me respondieron que nos iban a mandar algo mientras nos pagan. (1970, p.55)

El patrón de la finca no ha dispuesto más trabajo debido a una serie de problemas que tiene en la capital, no se menciona qué tipos de problemas, pero a raíz de eso, los hombres solo pueden esperar por una solución. Sin embargo, las necesidades cotidianas de sus familias se hacen presentes; no tienen como pagar sus deudas y ya nadie les da fiado. En la reunión, la voz de un joven se introduce y alega que ellos deberían participar más y luchar por lo que les corresponde; no obstante, hay miedo por parte de algunos miembros del grupo al pensar en las futuras consecuencias

Llevo a la espalda muchos años de experiencia. Que los gobiernos, que las leyes, que las campañas políticas donde nos ofrecen todo y lo que agarramos es el trago y los diez pesos de las votaciones. Fíjense que siempre quedamos igual o más jodidos que antes. Por eso yo digo que lo mejor es quedarnos tranquilos o irnos a hablar con el patrón a ver si por las buenas nos deja trabajar (1970, p. 56) 
La situación límite de este problema se presenta en el cuento "Cama número siete", en el cual un hombre tuberculoso no puede trabajar debido a su enfermedad. Dicha impotencia tortura al hombre que piensa que es mejor matar a sus hijos, a que sigan teniendo vida y sufran hambre y miseria "ayer cuando se fueron los doctores, grité que deseaba matar a mis hijos para que no tuvieran que vivir las cosas horribles que yo he pasado. Me trataron de loco y me pusieron una inyección para dormir" (1970, p.119).

También, es importante referirse a que por la falta de trabajo y de un salario digno se presentan otras problemáticas sociales como: carencia en los servicios médicos, alfabetismo, violencia doméstica, entre muchos otros. Asimismo, hay algunos cuentos como "Un maleficio", "Desobediencia" y "Fuga" que tratan sobre situaciones cotidianas y creencias de la sociedad costarricense. Por ejemplo: hay referencias a leyendas, curanderos y brujerías.

\section{A la vuelta de la esquina}

La esquina es un espacio público que sirve de tránsito social, punto de reunión y convocatoria. El título A la vuelta de la esquina nos sugiere un movimiento en el espacio, que en esta oportunidad, se refiere al urbano. Asimismo, es allí en donde convergen voces y personajes de clases sociales distintas y que por ser un lugar de paso, permite acercarnos a la diversidad del zoo humano josefino: prostitutas, maquiladoras, niños huérfanos, alcohólicos, curas, ladrones, entre otros.

Uno de los elementos más interesantes del cuentario es la presentación de nuevos espacios dentro de la geografía urbana. En "Un baile" y "Center City", los cuentos se ubican en un bar. El primer cuento presenta la vida de una prostituta llamada Florinda que debe trabajar esa noche porque le urge conseguir dinero para mantener a su pequeña hija, no obstante, se encuentra embarazada y para ocultarlo, utiliza unas fajas con las que esconden su vientre. La construcción del espacio es esperpéntica. La oscuridad, la música y el alcohol se conjugan para crear un espacio que trasgrede las normas sociales. La expresión de una sexualidad exagerada, en donde los cuerpos son sujetos de una búsqueda instintiva por el placer sexual, domina a los hombres y mujeres que conforman la escena

Las notas estridentes de la música repercuten en los vidrios opacos de las ventanas, se mezclan con el sudor de las parejas, entre el ritmo de los zapatos, en las muecas de algunas caras y la risa, abundante, en otras. El color negro, húmedo, se balancea con mayor lujuria que el color blanco y el golpe del tambor como un eco de épocas pasada, continúa adherido a la música (1970, p.31)

Florinda encuentra a un hombre, al que puede engañar para que no note su barriga crecida. Mientras bailan, ella sufre un desmayo. En el siguiente párrafo, se describe a las mujeres intentando quitarle las fajas a Florinda y los gritos de un niño al fondo del salón. En "Center City", el personaje de Eugenio busca presentarse en un bar josefino de clamada popularidad para darse a conocer como cantante. De manera similar al cuento anterior, el bar se convierte en un umbral para el carnaval: alcohol, música y algarabía desborda en el ambiente. El público es quien dictamina que artistas son los que merecen estar en el escenario por medio de sus gritos y voces. El cuento concluye justo en el momento en que Eugenio va a cantar.

En algunos de los cuentos, se realiza una descripción de los barrios más pobres que conforman la ciudad capitalina. En "Sed" se menciona "Por ser un barrio pobre, te aseguro que en otros tiempos pasa el camión a tiempo. Igual que con el agua, hace tres días no viene y no tengo trastos limpios ¡Olor a basura!" (1975, p. 14). También en "La bendición de la mañana", el personaje del Padre, quién es el narrador del cuento, menciona

$\mathrm{Y}$ en fila por lo angosto del camino, me guiaron entre aquella maraña de callejuelas irregulares con restos de basura, periódicos arrugados, las miradas curiosas de las gentes que se asomaban por las puertas de las casuchas de madera de colores desteñidos, ventanas sin vidrios, zinc herrumbrado y esa fila de chiquillos sucios con caras maliciosas (1975, p.50) 
El mercado también es un lugar representativo de la urbanidad, sitio por excelencia del comercio. En “¿Le llevo doña?”, el mercado es descrito a partir de la variedad de productos y del constante vaivén de las personas "Se levanta al encuentro de la gente que inunda otra vez el mercado, en su afán de comprar. Las vendedoras presentan sus caras risueñas y ofrecen sus mercancías. Las gentes pasan sin hacer caso a esas voces insinuantes, a los gestos que intentan detenerlas" (1975: p. 169). Asimismo, hay un uso de avenidas y calles de San José centro. Los personajes recorren el espacio y se desplazan constantemente. Por ejemplo, en "Pedro" y "El hilo de la mañana", ambos protagonistas hacen un recorrido por la ciudad, mientras se dirigen a sus respectivos trabajos.

El lenguaje utilizado por los personajes es coloquial. Se utilizan frases y expresiones populares. En "Animalito" la figura del personaje se asemeja a la del pachuco ${ }^{3}$. Es un hombre que proviene de un estrato social bajo, sin educación y que se ha consagrado como un ladrón muy hábil. El cuento consiste en casi un monólogo del personaje sobre su recién salida de la cárcel: "Dos tombos entran y sin decir nada me agarran a batonazos. Respondo a patadas, jodo a uno en mal lugar, miviejita viene a ayudarme pero me joden en la cabeza con el batón y caigo medio atarantado" (1975, p. 62).

El espacio del hogar ya no es valorado. La familia como núcleo representativo de la sociedad costarricense comienza a sufrir fisuras a partir de un descrédito hacia el modelo de organización tradicional. Los hombres ya no cumplen con su rol tradicional de proveedores y son incapaces de identificarse en dicho papel. En el cuento de "El enderezador", se narra la determinación de Eugenio, quien ha sido un alcohólico toda su vida, de no seguir tomando más, algunas de sus reflexiones son

\footnotetext{
Ahora sí está decidido a no beber más. Necesita el dinero para ayudar a Toñillo a entrar a la universidad. La profesora le había dicho que es muy inteligente: "Presentó los mejores exámenes de toda la clase y tiene que seguir estudiando". De sólo imaginarse que un hijo suyo pueda llegar a ser doctor o abogado, se le llenan los ojos de agua.
}

\begin{abstract}
Debe comprarle ropa nueva y hasta un traje entero para no desmerezca a los ojos de los demás. Para ello tiene que dejar el licor, los compañeros de farra y las madrugadas de voces melosas y pechos tibios. (1975, p. 124)
\end{abstract}

No obstante, la buena voluntad Eugenio termina cuando sus mismos compañeros de tragos le proponen una copita al haber concluido con el trabajo en el taller. Eugenio no se resiste ante la propuesta. Pablo, el padre de los hijos del cuento "Un largo camino", también está ausente y cuando llega a la casa, casi siempre esta borracho. En este caso, también la madre es alcohólica, los niños son testigos de la violencia familiar "Él llora en un rincón. No es la primera vez que ha presenciado una paliza y hasta un golpe fuerte recibió el día que quiso defenderla. Lo que nunca pudo entender es por qué, después de golpearla hasta que caía al suelo, la abrazaba y la besaba, diciéndole que no podía vivir si ella" (1975, p.72).

Las mujeres generalmente son madres solteras. Hay dos posibilidades: no tienen maridos o ellos están ausentes. En "Un baile", "La bendición de la tarde", "Sed" y "Un largo camino" las figuras femeninas tienen que salir de los hogares para tomar un papel más protagónico.

Los niños se ven forzados a trabajar desde muy jóvenes, ya que deben ganar dinero para ayudar a la alimentación de sus demás hermanos e incluso su madre. El cuento "¿Le limpió don?" trata sobre la historia de dos niños que son limpiabotas y que intentan ayudar a su padre en las necesidades del hogar. Trabajar en la calle es la única manera que tiene este niño para sobrevivir, a pesar del peligro que corre de ser atrapado por la policía o por los matones "Por la Avenida Central, no hay duda. Está repleta de gente y como él es pequeño y delgado le es fácil escurrirse entre la multitud. Esa noche no irá a su casa, se entregará a la patrulla verdad para que lo lleven a dormir al tabo. Allí va a estar salvo de los matones y mañana comenzará el oficio bien temprano" (1975, p. 91).

El cuento "¿Le llevó, doña?" narra las dificultades que tiene un niño que trabaja en el Mercado Central, llevando las bolsas de 
mujeres que compran verduras. El niño vino a la ciudad con su madre y hermanos, por la insistencia de Esteban, el novio de su mamá, que al final los abandona debajo de un puente. La competencia por llevar las bolsas es feroz, pues hay muchos niños como él que también deben de conseguir dinero:

\begin{abstract}
"Sos un inútil" le dice su madre, "no traes casi nada de dinero a la casa. Yo conozco chiquillos que ganan hasta diez pesos diarios." Él también los ha visto y ha sentido sus empujones, ese hacerlo a un lado mientras lado: "Yo, yo, señora, yo estaba primero". Y su voz está impregnada en lágrimas cuando dice “Le llevo, doña?” a la próxima señora que se le acerca. Le gustaría contarle dónde vive, los miedos que pasan él y sus hermanos cuando él río crece y se acerca cautelosamente a la entrada de la casa. $(1975$, p. 167).
\end{abstract}

El cuento "Navidad 1973" trata sobre dos hermanos huérfanos que viven de las limosnas que recogen en la calle. Ofelia ha visto una muñeca en un escaparate de una tienda que quiere para Navidad, todos los días de diciembre pasa por la tienda con la esperanza de que nadie la compre. Sin embargo, el veinticuatro de diciembre, una señora entra a la tienda y se lleva la muñeca. En el texto, se observa muy bien las dificultades que envuelven la vida de los niños en la calle.

\section{En diálogo}

En el primer cuentario, hay un interés por denunciar más explícitamente problemáticas relacionadas con el desempleo, la carencia en salud pública, la persecución de grupos de izquierda y políticas injustas por parte del gobierno. En el segundo cuentario, el foco de la narración no recurre a la problemática en sí, sino que se centra más en la peculiaridad de la vida de los protagonistas, la problemática es abordada de manera implícita. A modo de ilustración:

En eso comienza a ver luces que se encienden y se apagan. Son pequeñas como chispas pero van creciendo hasta explotar en una lluvia de colores (...) Se acercan hasta rozarle la cara y al penetrar en su cuerpo hacen tantas cosquillas que tiene que estallar en carcajadas. Intenta levantarse para correr hasta la casa de Ismael y contarle que al fin ve los colores del aire pero cae de bruces en el suelo (1975, p.17).

Este ejemplo tomado del cuento "Sed" narra la historia de un niño que se encuentra solo en su casa y que tiene sed porque no hay agua que tomar debido a que el barrio en que vive no cuenta con el servicio de agua potable. Así, que en la búsqueda del niño por agua, descubre una botella de alcohol perteneciente a su padre y sin saber qué clase de bebida tomaba, el niño se emborracha. Las "luces de colores" que tanto Ismael y el protagonista ven son efectos de un alcoholismo infantil.

A nivel de la organización interna, el primer cuentario apela estructuras y valores de una sociedad tradicional, en la que la familia es la base de la organización social. Hay un predominio de la figura masculina. Este es un elemento importante que en el segundo cuentario cambia por completo, ya que se evidencia una ruptura de dicha estructura familia (niños huérfanos y madres solteras).

En el cuentario Los marginados, la voz del narrador utiliza un lenguaje poético y artificioso en la descripción del espacio, en el que los personajes no tienen casi una participación directa. Lo anterior cambia en A la vuelta de la esquina, en donde primero la intervención del narrador disminuye y segundo, hay un mayor uso del lenguaje coloquial pues se reproduce la psique de los personajes. Este aspecto permite hablar de una polifonía de voces que compone el texto y que pretende ejemplificar ciertos grupos sociales.

En los dos cuentarios, la mayoría de historias ocurren en un presente, sin embargo, hay interrupciones temporales que generalmente son analepsis, las cuales tienen la función de explicarnos la razón por la cual el personaje actúa de esa manera o aportan algún elemento que permita entender la narración en su tiempo actual. A saber: "Un chiquillo toca su pantalón mientras otro, con voz quejumbrosa, le pide una limosna. La moneda pasa de su mano limpia, de uñas recién cortadas, a aquella otra de bordes negros. Tenía esa edad once años, hasta la misma 
figura desgarbada cuando llegó al chispero y por primera vez entre manos y bocas sabias aprendió el misterio de los cuerpos" (1975, p. 147).

Es importante señalar la presencia de los personajes infantiles en "Fuga", "Granizo", "El regalo" y "Rosa María" de Los Marginados, pues son referentes previos para los protagonistas de "Sed”, “Le llevó, doña?”, “Le limpió, don?” y "Navidad 1973" de A la vuelta de la esquina.

En Los marginados, el espacio en que se sitúa la narración generalmente es el rural, hecho sumamente significativo que se comparte de las décadas anteriores. No obstante, en A la vuelta de la esquina, los espacios son principalmente urbanos.

\section{4. ¿Conclusiones?}

Continuando con una veta realista, los cuentarios Los marginados (1970) y A la vuelta de la esquina (1975) presentan imágenes fragmentarias de la realidad costarricense de las décadas de los sesenta y setenta. La literatura ya no es vista solamente como medio para transmitir denuncias políticas y sociales, sino también como un espacio para la reflexión.

De hecho, queda pendiente extender el análisis a otros textos narrativos de la autora con el fin de señalar reelaboraciones en personajes y espacios. Hay una temática que podría abordarse en futuros trabajos, la cual es la representación de la violencia principalmente doméstica que se aprecia en los dos libros.

Asimismo, se observa una transición en la narrativa de Julieta Pinto, pues pasa de un texto de temática rural y de denuncia hacia una nueva problematización del espacio urbano. Ambos cuentarios nos acercan a la realidad de los personajes a partir de un sentimiento de solidaridad, pues como lectores presenciamos las tragedias de grupos ignorados por el discurso oficial.

\section{Notas}

1. Abelardo Bonilla menciona "La literatura costarricense nace con el realismo, en los últimos años del siglo XIX y en los primeros del actual (...) Es interesante anotar que las letras costarricenses, retrasadas en los siglos anteriores con relación a los demás o a la mayoría de los países hispanoamericanos, hasta ignorar del todo el movimiento romántico, coincidieron, sin embargo, con los pueblos más avanzados al iniciar el movimiento realista, guardadas proporciones" (1981, p.109).

2. Con el término situaciones límite me refiero a acontecimientos que generalmente son extremos como la muerte, la enfermedad termina, una peste, violencia doméstica.

3. Sobre la figura del pachuco Álvaro Quesada señala: "Nuevos patrones culturales, asociados a las nuevas culturas de masas y a las clases medias y populares urbanas --cuyo estereotipo negativo sería la figura del "pachuco"- se difunden y ganan espacio en la ciudad, ante el desconcierto, la curiosidad o el disgusto de las viejas élites o los intelectuales, quienes veían modificarse vertiginosamente o desaparecer los rasgos físicos y culturales que habían caracterizado la fisonomía tradicional del país desde fines del siglo pasado" (2000, p. 21).

\section{Referencias}

Bonilla, Abelardo. 1981. Historia de la literatura costarricense. San José: Editorial Autónoma de Centro América.

Diccionario de la Real Academia Española. Consulta en línea: http://dle.rae. es/?id=OOn9sZS

Quesada Soto, Álvaro. 2000. "La narrativa costarricense de finales de siglo". Revista Letras, 32, (14-41). 
Rojas, Margarita y Ovares, Flora. 1995. 100 años de literatura costarricense. San José: Editorial Farben.

Picado, Manuel. 1983. Literatura, ideología, crítica: notas para un estudio de la literatura costarricense. San José: Editorial Costa Rica.
Pinto, Julieta. 1970. Los marginados. San José: Editorial Conciencia Nueva.

Pinto, Julieta. 1975. A la vuelta de la esquina. Heredia: Editorial de la Universidad Nacional.

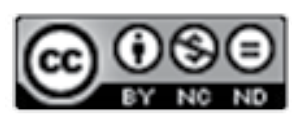

Este obra está bajo una licencia de Creative Commons

Reconocimiento-NoComercial-SinObraDerivada 4.0 Internacional. 
